\title{
Prior infection by seasonal coronaviruses, as assessed by serology, does not prevent SARS-CoV-2 infection and disease in children, France, April to June 2020
}

Isabelle Sermet-Gaudelus ${ }^{1,2,3,4}$, Sarah Temmam ${ }^{4,5}$, Christèle Huon ${ }^{5}$, Sylvie Behillil ${ }^{6,7}$, Vincent Gajdos ${ }^{8,9}$, Thomas Bigot ${ }^{5,10}$,

Thibaut Lurier ${ }^{11,12,13}$, Delphine Chrétien ${ }^{5}$, Marija Backovic ${ }^{14}$, Agnès Delaunay-Moisan ${ }^{15}$, Flora Donati ${ }^{6,7}$, Mélanie Albert ${ }^{6,7}$, Elsa Foucaud $^{16}$, Bettina Mesplées ${ }^{17}$, Grégoire Benoist ${ }^{18}$, Albert Faye ${ }^{19}$, Marc Duval-Arnould ${ }^{20}$, Célia Cretolle ${ }^{2}$, Marina Charbit ${ }^{2}$,

Mélodie Aubart ${ }^{2}$, Johanne Auriau², Mathie Lorrot ${ }^{21}$, Dulanjalee Kariyawasam² , Laura Fertitta², Gilles Orliaguet ${ }^{2}$, Bénédicte Pigneur $^{2}$, Brigitte Bader-Meunier ${ }^{2}$, Coralie Briand ${ }^{17}$, Vincent Enouf ${ }^{6,7,22}$, Julie Toubiana ${ }^{2,3,23}$, Tiffany Guilleminot ${ }^{24}$, Sylvie van der Werf6,7, Marianne Leruez-Ville ${ }^{24}$, Marc Eloit ${ }^{5,25}$

1. Institut Necker Enfants Malades, INSERM U 1171, Paris, France

2. Hôpital Necker-Enfants Malades, Assistance Publique Hôpitaux de Paris, Paris, France

3. Université de Paris, Paris, France

4. These authors contributed equally to the work

5. Pathogen Discovery Laboratory, Department of Virology, Institut Pasteur, Paris, France

6. Molecular Genetics of RNA Viruses, Department of Virology, CNRS UMR3569, Université de Paris, Institut Pasteur, Paris, France

7. National Reference Center for Respiratory Viruses, Institut Pasteur, Paris, France

8. Hôpital Antoine Beclere, Clamart, France

9. Centre for Research in Epidemiology and Population Health, INSERM UMR1018, Villejuif, France

10. Hub de Bioinformatique et Biostatistique - Département Biologie Computationnelle, Institut Pasteur, USR 3756 CNRS, Paris, France

11. Université Clermont Auvergne, INRAE, VetAgro Sup, UMR EPIA, Saint-Genès-Champanelle, France

12. Université de Lyon, INRAE, VetAgro Sup, UMR EPIA, Marcy l'Etoile, France

13. Université de Lyon, INRAE, VetAgro Sup, Usc 1233 UR RS2GP, Marcy l'Etoile, France

14. Unité de Virologie Structurale, Institut Pasteur, Département de Virologie, CNRS, UMR3569, Paris, France

15. Université Paris-Saclay, CEA, CNRS, Institute for Integrative Biology of the Cell (I2BC), Gif-sur-Yvette, France

16. Hôpital Jean Verdier, Bondy, France

17. Hôpital Louis Mourier, Colombes, France

18. Hôpital Ambroise Paré, Boulogne Billancourt, France

19. Hôpital Robert Debré, Paris, France

20. Hôpital Kremlin Bicêtre, Le Kremlin-Bicêtre, France

21. Hôpital Armand Trousseau, Paris, France

22. Plateforme de microbiologie mutualisée (P2M), Pasteur International Bioresources Network (PIBnet), Institut Pasteur, Paris, France

23. Unité Biodiversité et Epidemiologie des Bacteries Pathogènes, Institut Pasteur, Paris, France

24. Laboratoire de Microbiologie, Hôpital Necker-Enfants Malades, Paris, France

25. Ecole Nationale Vétérinaire d'Alfort, Maisons Alfort, France

Correspondence: Marc Eloit (marc.eloit@pasteur.fr)

Citation style for this article:

Sermet-Gaudelus Isabelle, Temmam Sarah, Huon Christèle, Behillil Sylvie, Gajdos Vincent, Bigot Thomas, Lurier Thibaut, Chrétien Delphine, Backovic Marija, Delaunay-Moisan Agnès, Donati Flora, Albert Mélanie, Foucaud Elsa, Mesplées Bettina, Benoist Grégoire, Faye Albert, Duval-Arnould Marc, Cretolle Célia, Charbit Marina, Aubart Mélodie, Auriau Johanne, Lorrot Mathie, Kariyawasam Dulanjalee, Fertitta Laura, Orliaguet Gilles, Pigneur Bénédicte, Bader-Meunier Brigitte, Briand Coralie, Enouf Vincent, Toubiana Julie, Guilleminot Tiffany, van der Werf Sylvie, Leruez-Ville Marianne, Eloit Marc. Prior infection by seasonal coronaviruses, as assessed by serology, does not prevent SARS-CoV-2 infection and disease in children, France, April to June 2020. Euro Surveill. 2021;26(13):pii=2001782. https://doi.org/10.2807/1560-7917.ES.2021.26.13.2001782

Background: Children have a low rate of COVID-19 and secondary severe multisystem inflammatory syndrome (MIS) but present a high prevalence of symptomatic seasonal coronavirus infections. Aim: We tested if prior infections by seasonal coronaviruses ( $\mathrm{HCoV}$ ) $\mathrm{NL}_{3}$, $\mathrm{HKU}_{1}, 229 \mathrm{E}$ or $\mathrm{OC}_{43}$ as assessed by serology, provide cross-protective immunity against SARS-CoV-2 infection. Methods: We set a cross-sectional observational multicentric study in pauci- or asymptomatic children hospitalised in Paris during the first wave for reasons other than COVID (hospitalised children (HOS), $n=739$ ) plus children presenting with MIS $(n=36)$. SARS-CoV-2 antibodies directed against the nucleoprotein $(\mathrm{N})$ and $\mathrm{S}_{1}$ and $\mathrm{S} 2$ domains of the spike (S) proteins were monitored by an in-house luciferase immunoprecipitation system assay. We randomly selected 69 SARS-CoV-2seropositive patients (including 15 with MIS) and 115 matched SARS-CoV-2-seronegative patients (controls (CTL)). We measured antibodies against SARS-CoV-2 and $\mathrm{HCoV}$ as evidence for prior corresponding infections and assessed if SARS-CoV-2 prevalence of infection and levels of antibody responses were shaped by prior seasonal coronavirus infections. Results: Prevalence of $\mathrm{HCoV}$ infections were similar in HOS, MIS and CTL groups. Antibody levels against HCoV were not significantly different in the three groups and were not related to the level of SARS-CoV-2 antibodies in the HOS and MIS groups. SARS-CoV-2 antibody profiles were different between HOS and MIS children. Conclusion: Prior infection by seasonal coronaviruses, 
as assessed by serology, does not interfere with SARS-CoV-2 infection and related MIS in children.

\section{Introduction}

Coronavirus disease (COVID-19) is caused by infection with severe acute respiratory coronavirus 2 (SARS-CoV-2), a betacoronavirus of the subgenus Sarbecovirus [1], which has expanded worldwide since its emergence in China at the end of 2019. Observations indicate that children are less likely to develop the disease and that the clinical course of COVID-19 in children is less severe than in adults, but the reason why is still unknown [2-4]. Children represent only $0.6-2.3 \%$ of confirmed cases in China and $0.8-5.2 \%$ outside China, excluding household contacts $[2,5,6]$. As asymptomatic or mildly symptomatic children are underdiagnosed and their viral loads are comparable to those of adults, it is still uncertain whether children may act as an asymptomatic reservoir for the spread of the virus to their adult and elderly relatives [7,8], albeit with low efficacy [9-13]. It has also been suggested that children's susceptibility to infection might be low [5]. This might be related to infections with seasonal human coronaviruses (HCoV) which are frequent at a very young age and result in mild respiratory infections $[14,15]$. They could lead to cross-protective immunity in children, mediated either by cross-binding or cross-neutralising antibodies [16] or by T-cell responses that target epitopes shared by SARS-CoV-2 and $\mathrm{HCOV}[17,18]$. Indeed, it has recently been shown that $\mathrm{CD}_{4}{ }^{+} \mathrm{T}$-cells of unexposed subjects (sampled before the pandemic) recognised SARSCoV-2 [17].

Cases of multisystem inflammatory syndrome (MIS) have been reported in children that were infected by SARS-CoV-2 or were in contact with COVID-19 patients $[19,20]$. As for seasonal coronaviruses [21], it is possible that a low antibody response to SARS-CoV-2 or cross-reactive antibodies facilitate immune-dependent enhancement following re-exposure, potentiated by a specific genetic background [22,23]. Interestingly, a domain of the SARS-CoV-2 spike protein which binds with high affinity to T-cells may act as a super antigen and trigger excessive adaptive immune responses [24].

The aim of this study was to analyse the impact of endemic seasonal coronavirus infection on SARSCoV-2 infection in children by investigating in depth the typology of respective humoral responses, based on a luciferase immunoprecipitation system (LIPS) assay targeting the spike (S) and the nucleoprotein (N) of SARS-CoV-2 [22] and the four seasonal coronaviruses. We measured if prior infections with $\mathrm{HCoV}$, evidenced by antibody responses, modulate the risk of SARS-CoV-2 infection by analysing the frequency and the level of response in SARS-CoV-2-positive children as compared with SARS-CoV-2-negative matched controls. We also analysed humoral responses against SARS-CoV-2 and seasonal HCoV in patients with MIS regarding antibody targets.

\section{Methods}

\section{Cohort design}

Paediatric patients aged $0-18$ years consulting or hospitalised for any disease other than COVID-19 for at most 4 days in paediatric tertiary healthcare departments of the Assistance Publique-Hôpitaux de Paris between 1 April and 1 June 2020 were included in an ongoing prospective multicentric observational seroprevalence study. We considered all patients presenting with a MIS disease, as defined by the American Heart Association [25].

To detect previous SARS-CoV-2 infection, we used an in-house LIPS assay targeting domain $\mathrm{S}_{1}$ of the $\mathrm{S}$ protein and the C-terminal part of the $\mathrm{N}$ protein as first line, as previously described [26]. The overall sensitivity of the LIPS assay was further improved by including the detection of antibodies against the S2 subdomain (Supplement). We identified three sub-cohorts of 54 SARS-CoV-2-seropositive hospitalised children (HOSP), 15 SARS-CoV-2-seropositive children with MIS (MIS-P) and 115 SARS-CoV-2-seronegative children as controls (CTL), matched for their age and sex.

\section{Serological assays}

To measure if prior infections with $\mathrm{HCoV}$ could influence the SARS-CoV-2 antibody response, the LIPS assays were extended to detect additional antibodies directed against the full $\mathrm{S}$ ectodomain (in a prefusion conformation) of SARS-CoV-2, the two human betacoronaviruses (HKU1 and $\mathrm{OC}_{43}$ ) and one human alphacoronavirus (229E). Assays similar to SARS-CoV-2 LIPS-N were also designed for the four $\mathrm{HCoV}$, including the alphacoronavirus NL63. Detailed technical information is given in Supplement part 1. The sensitivity and specificity of the first line SARS-CoV-2 LIPS test (defined as a positive detection for either $\mathrm{S}_{1}, \mathrm{~S}_{2}$ or $\mathrm{N}$ antigen) used to include the patients was $88 \%$ and $95.6 \%$, respectively. Sensitivity and specificity calculation of all assays are detailed in Supplement part 2.

\section{Statistical analysis}

Statistical analyses were conducted with GraphPad Prism 8 (GraphPad Software, San Diego). The signalto-noise light unit (LU) ratios between the three groups of children were compared using the Kruskal-Wallis ANOVA and Dunn's multiple comparisons tests for each antigen considered. Significant differences of seroprevalence between groups were calculated using Fisher's exact test. Two-sided $p$ value $<0.05$ was considered as significant. Principal component analysis (PCA) was performed to identify the serological profile according to SARS-CoV-2 antibodies and seasonal $\mathrm{HCoV}$ antibodies. Data were processed with R 3.6.3 [27] using GGPlot2 with GGally for matrices of plots, and ggfortify for PCA plots packages.

\section{Ethical statement}

The local Ethics committee (CERAPHP Paris V) approved this study (IRB registration: \#00011928). Serology was 


\section{TABLE 1}

Demographic and clinical characteristics of the different groups of SARS-CoV-2-seropositive and -seronegative children, France, April-June 2020 ( $\mathrm{n}=184)$

\begin{tabular}{|c|c|c|c|c|c|c|c|c|c|}
\hline & \multicolumn{2}{|c|}{$\begin{array}{c}\text { HOS-P } \\
\begin{array}{c}\text { SARS-CoV-2-positive } \\
n=54\end{array}\end{array}$} & \multicolumn{2}{|c|}{$\begin{array}{c}\text { MIS-P } \\
\text { SARS-CoV-2- } \\
\text { positive } \\
n=15\end{array}$} & \multicolumn{2}{|c|}{$\begin{array}{c}\text { CTL } \\
\begin{array}{l}\text { SARS-CoV-2- } \\
\text { negative } \\
n=115\end{array}\end{array}$} & \multirow[t]{2}{*}{$\begin{array}{c}p \text { (HOS-P vs } \\
\text { CTL) }\end{array}$} & \multirow[t]{2}{*}{$\begin{array}{l}\mathrm{p} \text { (MIS-P vs } \\
\text { CTL) }\end{array}$} & \multirow[t]{2}{*}{$\begin{array}{l}\mathrm{p}(\mathrm{HOS}-\mathrm{P} \text { vS } \\
\text { MIS-P) }\end{array}$} \\
\hline & $n$ & $\%$ & $\mathrm{n}$ & $\%$ & $\mathrm{n}$ & $\%$ & & & \\
\hline \multicolumn{10}{|l|}{ Demographic characteristics } \\
\hline $\begin{array}{l}\text { Age in years: } \\
\text { mean (SD) (min-max) }\end{array}$ & \multicolumn{2}{|c|}{$9.8(5.5)(0-18)$} & \multicolumn{2}{|c|}{$8.6(3.4)(3-14)$} & \multicolumn{2}{|c|}{$9.6(5.2)(0-18)$} & NS & NS & NS \\
\hline Male sex & 25 & 46 & 5 & 33 & 63 & 55 & NS & NS & NS \\
\hline \multicolumn{10}{|l|}{ Reason for hospitalisation } \\
\hline Systematic monitoring & 30 & 56 & 0 & 0 & 61 & 53 & NS & $<10-4$ & $<10-4$ \\
\hline Paediatric emergency & 6 & 11 & 14 & 93 & 7 & 6 & NS & $<10-6$ & $<10-6$ \\
\hline Surgery & 6 & 11 & 0 & 0 & 16 & 14 & NS & NS & NS \\
\hline Chronic disease exacerbation & 2 & 4 & 0 & 0 & 0 & 0 & NS & NS & NS \\
\hline \multicolumn{10}{|l|}{ Comorbidities } \\
\hline No comorbidity & 32 & 59 & 13 & 87 & 63 & 55 & NS & 0.02 & $<10-4$ \\
\hline Diabetes & 2 & 4 & 0 & 0 & 4 & 3 & NS & NS & NS \\
\hline Immunosuppression & 8 & 15 & 0 & 0 & 8 & 7 & NS & NS & 0.005 \\
\hline Cancer in the 3 previous years & 6 & 11 & 0 & 0 & 3 & 3 & 0.02 & NS & NS \\
\hline Others & 22 & 41 & 2 & 13 & 37 & 32 & NS & NS & NS \\
\hline \multicolumn{10}{|c|}{ History consistent with COVID-19 in the 3 previous months ${ }^{a}$} \\
\hline Case contacts & 8 & 24 & 2 & 26 & 10 & 9 & 0.006 & NS & NS \\
\hline $\begin{array}{l}\text { Delay known exposure/sampling: } \\
\text { mean (SD) (min-max) }\end{array}$ & \multicolumn{2}{|c|}{$39.6(14.6)(32-71)$} & \multicolumn{2}{|c|}{$29(1.4)(28-30)$} & \multicolumn{2}{|c|}{ NA } & NA & NA & NA \\
\hline $\begin{array}{l}\text { Delay symptom onset/sampling: } \\
\text { mean (SD) (min-max) }\end{array}$ & \multicolumn{2}{|r|}{ NA } & \multicolumn{2}{|c|}{$29.9(16.7)(7-64)$} & \multicolumn{2}{|c|}{ NA } & NA & NA & NA \\
\hline No symptoms & 34 & 63 & 12 & 80 & 79 & 69 & NS & NS & NS \\
\hline Fever & 14 & 26 & 0 & 0 & 13 & 11 & 0.01 & NS & 0.04 \\
\hline $\begin{array}{l}\text { Diarrhoea, abdominal pain, } \\
\text { vomiting }\end{array}$ & 9 & 17 & 1 & 7 & 16 & 14 & NS & NS & NS \\
\hline Asthenia & 7 & 13 & 1 & 7 & 6 & 5 & 0.03 & NS & NS \\
\hline Cough & 2 & 4 & 0 & 0 & 6 & 5 & NS & NS & NS \\
\hline Dyspnoea/shortness of breath & 2 & 4 & 1 & 7 & 1 & 1 & NS & NS & NS \\
\hline Headache & 5 & 9 & 0 & 0 & 3 & 3 & NS & NS & NS \\
\hline Neuromuscular disorders & 7 & 13 & 1 & 7 & 5 & $4 \cdot 3$ & 0.03 & NS & NS \\
\hline Rhinopharyngitis & 5 & 9.2 & 0 & 0 & 5 & $4 \cdot 3$ & NS & NS & NS \\
\hline Dermatological symptoms & 4 & 7.4 & 0 & 0 & 5 & $4 \cdot 3$ & NS & NS & NS \\
\hline
\end{tabular}

COVID-19: coronavirus disease; CTL: SARS-CoV-2-seronegative control group; HOS-P: SARS-CoV-2-seropositive hospitalised patients who did not develop an MIS; MIS-P: SARS-CoV-2-seropositive patients with multisystemic inflammatory syndrome; NA: not available; NS: nonsignificant; SARS-CoV-2: severe acute respiratory syndrome coronavirus 2; SD: standard deviation.

a More than one answer was possible.

Data as mean (SD) or \%. 
Prevalence of antibodies to SARS-CoV-2 spike (full S ectodomain, S1 and S2 domains) and nucleoprotein in HOS-P, MIS-P and CTL children, France, April-June $2020(\mathrm{n}=184)$

\begin{tabular}{|c|c|c|c|c|c|c|c|c|c|}
\hline \multirow[t]{2}{*}{ Antigen } & \multicolumn{2}{|c|}{$\begin{array}{c}\text { HOS-P } \\
\text { SARS-CoV-2-positive } \\
n=54\end{array}$} & \multicolumn{2}{|c|}{$\begin{array}{l}\text { MIS-P } \\
\text { SARS-CoV-2- } \\
\text { positive } \\
n=15\end{array}$} & \multicolumn{2}{|c|}{$\begin{array}{c}\text { CTL } \\
\text { SARS-CoV-2-negative } \\
n=115\end{array}$} & \multirow[t]{2}{*}{$\begin{array}{l}p(C T L \text { vs } \\
\text { HOS-P) }\end{array}$} & \multirow[t]{2}{*}{$\mathrm{p}$ (CTL vs MIS-P) } & \multirow[t]{2}{*}{$\begin{array}{c}p(\text { HOS-P vs } \\
\text { MIS-P) }\end{array}$} \\
\hline & $n$ & $\%$ & $n$ & $\%$ & $n$ & $\%$ & & & \\
\hline $\mathrm{S}_{1}$ & 24 & $44 \cdot 4$ & 14 & 93.3 & 0 & 0.0 & $<0.0001$ & $<0.0001$ & 0.0008 \\
\hline $\mathrm{S} 2$ & 49 & 90.7 & 15 & 100 & 0 & 0.0 & $<0.0001$ & $<0.0001$ & NS \\
\hline $\mathrm{N}$ & 29 & 53.7 & 14 & 93.3 & 0 & 0.0 & $<0.0001$ & $<0.0001$ & 0.0058 \\
\hline $\mathrm{S}_{1}$ or $\mathrm{S}_{2}$ or $\mathrm{N}$ & 54 & 100 & 15 & 100 & 0 & 0.0 & $<0.0001$ & $<0.0001$ & NS \\
\hline Full S & 28 & 51.9 & 13 & 86.7 & 1 & 0.9 & $<0.0001$ & $<0.0001$ & 0.0181 \\
\hline
\end{tabular}

CTL: SARS-CoV-2-seronegative control group; HOS-P: SARS-CoV-2-seropositive hospitalised patients who did not develop an MIS; MIS-P: SARS-CoV-2-seropositive patients with multisystemic inflammatory syndrome; NS: non-significant; SARS-CoV-2: severe acute respiratory syndrome coronavirus 2 .

sampled for usual care and patients and/or their parents/guardians were informed about the study but did not have to provide consent, according the French legislation.

\section{Results}

\section{Patients}

Table 1 presents the demographic and clinical characteristics of 54 SARS-CoV-2-seropositive HOS-P children, 15 SARS-CoV-2-seropositive MIS-P children and 115 SARS-CoV-2-seronegative CTL children. The comparison between HOS-P and CTL did not show any significant differences for age, sex ratio or reasons for hospitalisation.

Sixty-three per cent of the seropositive patients did not report any history consistent with COVID-19 during the preceding weeks. Among those, the MIS-P did not report any COVID-19 symptoms. The only symptoms that were marginally but significantly reported in the previous months in seropositive children were fever, asthenia, and myalgia. MIS-P patients did not report underlying chronic diseases and were all hospitalised in emergency units. There was no case of COVID-19 symptoms recorded before the onset of MIS and MIS-P patients were sampled at the time of MIS symptom onset. The mean delay between initial symptom onset and the time of serum sampling for MIS-P was 29.9 days (standard deviation (SD): 16.7 days; range: 7-64 days) (Table 1). Seropositive patients (MIS-P and HOSP) reported significantly more case contacts in the 3 previous months. In total, 10 seropositive patients acknowledged known exposure with a mean delay of 37.5 days (SD: 14.4 days; range: $28-71$ days). Two of 15 MIS-P patients were confirmed by positive SARSCoV-2 RT-PCR at the time of hospitalisation for MIS. For the 13 remaining patients, two reported a known exposure, with a delay of 28 and 30 days, respectively. We cannot exclude another viral infection for these 15 patients, except that they were negative at the time of hospitalisation for human respiratory syncytial viruses, seasonal coronaviruses, parainfluenza and influenza viruses, metapneumovirus and rhinovirus/enterovirus in nasopharyngeal swabs.

\section{Immunoprofiling of SARS-CoV-2 infection in HOS-P and MIS-P children}

The prevalence of children seropositive for SARSCoV-2 S1, S2 or N differed between HOS-P and MIS-P children (Table 2). HOS-P patients were characterised by a dominant $\mathrm{S} 2$ response compared with responses to $\mathrm{S} 1, \mathrm{~N}$ and to the full $\mathrm{S}$ ectodomain, whereas MIS-P patients' antibodies were directed against N, S1 and $\mathrm{S} 2$ altogether. The profile of antibody responses to SARS-COV-2 in seropositive HOS-P and MIS-P patients is shown in Figure 1. Levels of SARS-CoV-2 antibodies against $\mathrm{N}$ and $\mathrm{S} 1$ were significantly higher in the MIS-P than in the HOS-P group.

\section{Relationship between SARS-CoV-2 and seasonal $\mathrm{HCoV}$ infections}

Prevalence rates of anti-S (and to a lesser extent of anti$\mathrm{N}$ ) antibodies were generally similar in the CTL, HOS-P and MIS-P groups for the two betacoronaviruses (HKU1 and $\mathrm{OC}_{43}$ ) and the two alphacoronaviruses (229E and NL63). The exception was the MIS-P group in which the prevalence of HKU1-N, OC43-N and 229 E-N antibodies was significantly higher than in the HOS-P or in the CTL groups (Table 3 ).

We reasoned that if prior infection with seasonal $\mathrm{HCOV}$ induced cross-reactive immunity, this should be reflected in lower SARS-CoV-2 antibody prevalence or lower antibody levels compared with HCoV-naïve patients. Our results did not show any significant difference between HOS-P and CTL patients regarding antibody levels to the four seasonal HCoV (Figure 2).

This observation was confirmed by the PCA analysis, which showed that the patient groups (HOS-P, MIS-P and $(T L)$ were only clustered by SARS-COV-2 antibodies 
SARS-CoV-2 antibody responses in HOS-P, MIS-P and CTL children, France, April-June 2020 (n =184)

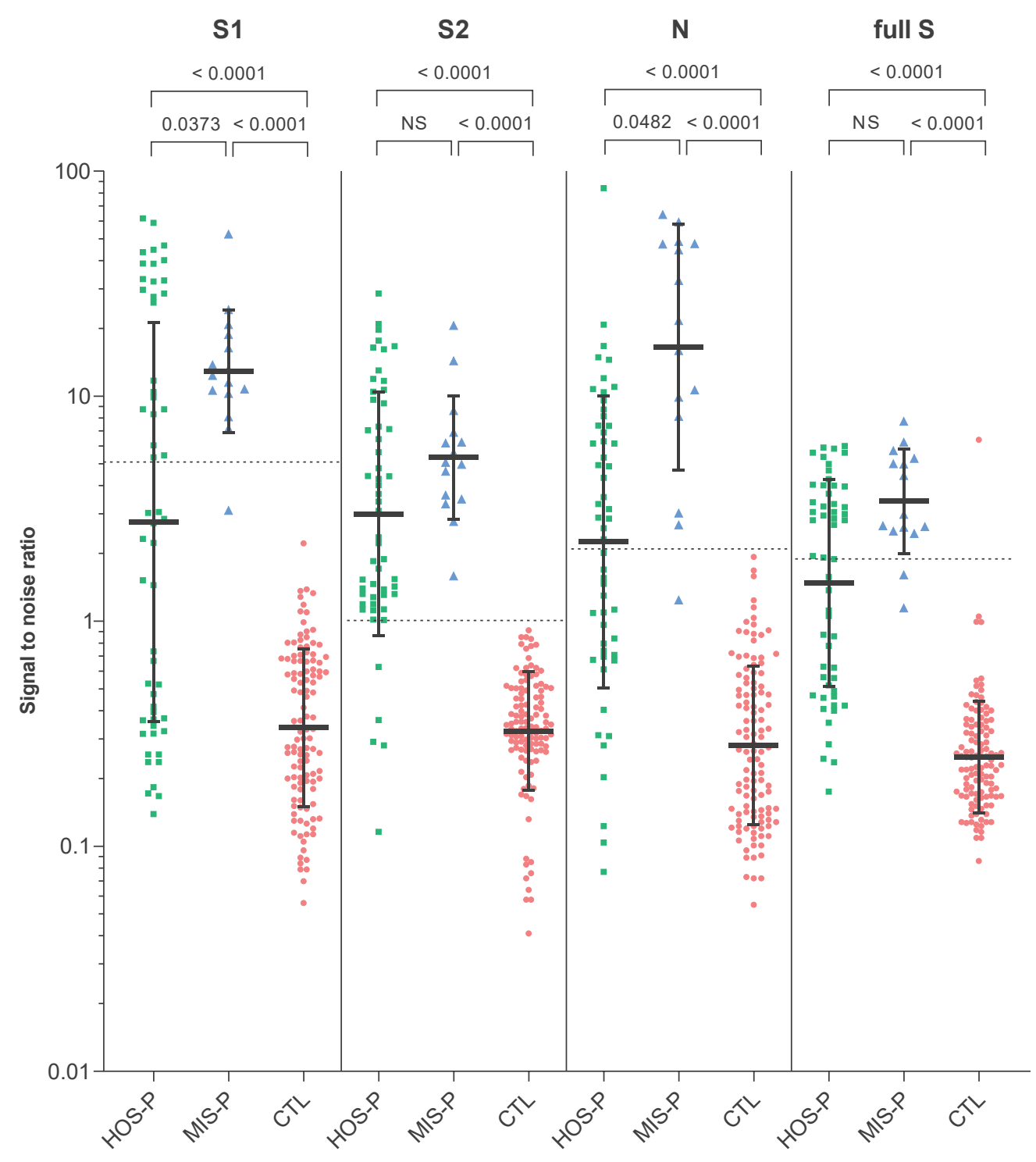

CTL: SARS-CoV-2-seronegative control group; HOS-P: SARS-CoV-2-seropositive hospitalised patients who did not develop an MIS; MIS-P: SARS-CoV-2-seropositive patients with multisystemic inflammatory syndrome; NS: non-significant; SARS-CoV-2: severe acute respiratory syndrome coronavirus 2 .

Green: HOS-P; blue: MIS-P; pink: CTL. Antibodies directed against S1, S2, N and full S ectodomain are described for each group of patients. The Kruskal-Wallis ANOVA and Dunn's multiple comparisons tests were performed for each antigen considered to compare the level of antibody response between the three groups.

and not by seasonal HCoV antibodies (Figure 3). Therefore, the frequency of SARS-CoV-2 infections and of related MIS diseases were not shaped by prior seasonal $\mathrm{HCoV}$ infections. In addition, there was no significant correlation between SARS-CoV-2 and seasonal HCoV antibody levels in HOS-P and MIS-P patients (Supplement, part 3). The level of SARS-CoV-2 antibodies to $\mathrm{N}$ and $\mathrm{S}$ were correlated, which corresponds to a good internal control. This was also the case for the $\mathrm{N}$ and $\mathrm{S}$ responses for each $\mathrm{HCoV}$, but to a lesser extent (Supplement, part 3).

\section{Discussion}

Observations indicate that children are less likely to develop COVID-19, and the clinical course of COVID-19 in children is less severe than in adults. To investigate reasons explaining decreased severity of SARS-CoV-2 infection in children, we studied the impact of prior infections with seasonal $\mathrm{HCOV}$ on the risk of infection by SARS-COV-2.

Seasonal HCoV include alphacoronaviruses (229E and NL63) and betacoronaviruses of lineage A (OC43 and 
Prevalence of antibodies to seasonal coronaviruses HKU1, OC43, NL63 and 229E spike and nucleoprotein in HOS-P, MIS-P and CTL children, France, April-June 2020 (n =184)

\begin{tabular}{|c|c|c|c|c|c|c|c|c|c|c|}
\hline \multirow[t]{2}{*}{ Virus } & \multirow[t]{2}{*}{ Antigen } & \multicolumn{2}{|c|}{$\begin{array}{c}\text { HOS-P } \\
\text { SARS-CoV-2-positive } \\
n=54\end{array}$} & \multicolumn{2}{|c|}{$\begin{array}{c}\text { MIS-P } \\
\text { SARS-CoV-2-positive } \\
n=15\end{array}$} & \multicolumn{2}{|c|}{$\begin{array}{c}\text { CTL } \\
\text { SARS-CoV-2-negative } \\
n=115\end{array}$} & \multirow[t]{2}{*}{$\begin{array}{c}p \text { (CTL vs } \\
\text { HOS -P) }\end{array}$} & \multirow[t]{2}{*}{$\begin{array}{c}\mathrm{p}(\mathrm{CTL} \text { vs } \\
\text { MIS-P) }\end{array}$} & \multirow[t]{2}{*}{$\begin{array}{c}\mathrm{p} \text { (HOS-P vS } \\
\text { MIS-P) }\end{array}$} \\
\hline & & $n$ & $\%$ & $n$ & $\%$ & $n$ & $\%$ & & & \\
\hline \multirow{2}{*}{ HCoV-HKU 1} & Full S & 46 & 85.2 & 15 & 100 & 100 & 87.0 & NS & NS & NS \\
\hline & $\mathrm{N}$ & 19 & 35.2 & 11 & 73.3 & 52 & 45.2 & NS & NS & 0.0166 \\
\hline \multirow{2}{*}{$\mathrm{HCoV}-\mathrm{OC} 43$} & Full S & 50 & 92.6 & 15 & 100 & 111 & 96.5 & NS & NS & NS \\
\hline & $\mathrm{N}$ & 18 & 33.3 & 12 & 80.0 & 47 & 40.9 & NS & 0.0053 & 0.0024 \\
\hline \multirow{2}{*}{$\mathrm{HCoV}-229 \mathrm{E}$} & Full S & 44 & 81.5 & 13 & 86.7 & 77 & 67.0 & NS & NS & NS \\
\hline & $\mathrm{N}$ & 12 & 22.2 & 9 & 60.0 & 34 & 29.6 & NS & 0.0372 & 0.0095 \\
\hline \multirow{2}{*}{ HCoV-NL63 } & Full S & NA & NA & NA & NA & NA & NA & NA & NA & NA \\
\hline & $\mathrm{N}$ & 49 & 90.7 & 14 & 93.3 & 101 & 87.8 & NS & NS & NS \\
\hline
\end{tabular}

CTL: SARS-CoV-2-seronegative control group; HOS-P: SARS-CoV-2-seropositive hospitalised patients who did not develop an MIS; MIS-P: SARS-CoV-2-seropositive patients with multisystemic inflammatory syndrome; HCoV: seasonal coronaviruses; NA: not applicable; NS: nonsignificant; SARS-CoV-2: severe acute respiratory syndrome coronavirus 2.

HKU1) which primarily replicate in the respiratory tract and mostly cause common colds [28]. These viruses show a worldwide distribution and multiple HCoV infections in various combinations are common [15,28-31]. Infection takes place in very early childhood, children experiencing cough, sore throat, fever and headache. Seroprevalence studies show very high prevalence rates, up to $100 \%$ in adult populations [15,32-34]. Our results also showed very high antibody prevalence and therefore we assume that infection by $\mathrm{HCoV}$ preceded infection by SARS-CoV-2 in our cohort, although the timing of those prior infections is unknown.

It has been suggested that previous seasonal HCoV infections could impact SARS-CoV-2 replication. We found no evidence of cross-protective immunity linked to previous infection with seasonal HCoV. Firstly, the seasonal HCoV prevalence in SARS-CoV-2-positive and -negative patients was similar. Secondly, there was no significant correlation between SARS-CoV-2 and antibody levels of any HCoV, whatever the antigen considered (S or N), while SARS-CoV-2 antibodies to $\mathrm{N}$ and $\mathrm{S}$ were correlated as expected.

It must be underlined that antibodies were considered as evidence of past infection by $\mathrm{HCoV}$, the intensity of the antibody response reflecting partly the degree of replication within the host, as an indicator of underlying cellular responses. Indeed, antibodies are unlikely to act as primary effectors of protection, as there is no or very low cross-neutralisation between these coronaviruses [16].

The lack of HCoV/SARS-CoV-2 cross-protection demonstrated here contrasts with the recent identification of pre-existing immune effectors recognising SARS-CoV-2 in healthy subjects sampled before the SARS-CoV-2 pandemic, notably T-helper $\mathrm{CD}_{4}^{+}$cells or IgG antibodies targeting the more conserved antigenic domains including the C-terminal part of S or the nucleoprotein $[18,35]$. A very sensitive cytometric assay reported frequent low levels of cross-reacting anti-S IgG, mainly targeting the S2 domain of the SARS-CoV-2 spike [16]. However, the clinical relevance of this result is questionable as it is based on a pseudo-neutralisation assay (SARS-CoV-2 pseudotyped lentiviruses expressing SARS-CoV-2 spike protein) in a non-respiratory cellular system (HEK293 cell line) and the mechanism of entry was not physiological because it did not involve the ACE2 receptor of the virus. In this context, our results obtained in a prospective multicentre paediatric study during the first pandemic wave in France are very relevant. They show that infection by endemic seasonal $\mathrm{HCoV}$, and therefore cross-reacting T-cells, do not seem to confer any significant protection against SARS-CoV-2 infection. Importantly, this also suggests that potentially crossreactive $\mathrm{CD}^{+}$or $\mathrm{CD}_{4}^{+} \mathrm{T}$-cells, which should be elicited upon seasonal HCoV infections as described in SARSCoV-2 infections [36], do not significantly contribute to protection against SARS-CoV-2 infection. However, our study based on a sample of 184 patients has several limitations as it revealed prior infections by $\mathrm{HCOV}$ and infections by SARS-CoV-2 but did not explore underlying mechanisms: (i) the $\mathrm{T}-\mathrm{CD}_{4}{ }^{+}$and $\mathrm{T}-\mathrm{CD} 8^{+}$cellular responses were not studied, (ii) despite providing evidence of past HCoV infection, the delay between $\mathrm{HCoV}$ infection and SARS-CoV-2 infection was unknown and (iii) the quality of the HCoV antibodies in terms of, for instance, their neutralisation potential was not known. As common colds and mild bronchitis caused by seasonal $\mathrm{HCoV}$ are experienced repeatedly, we need to question whether coronavirus infections induce a long-term clinically protective immune response based on antibody responses or on other immune effectors. 
Antibody responses against seasonal HCoV in HOS-P, MIS-P and CTL children, France, April-June 2020 (n =184)

A. Full Sectodomain

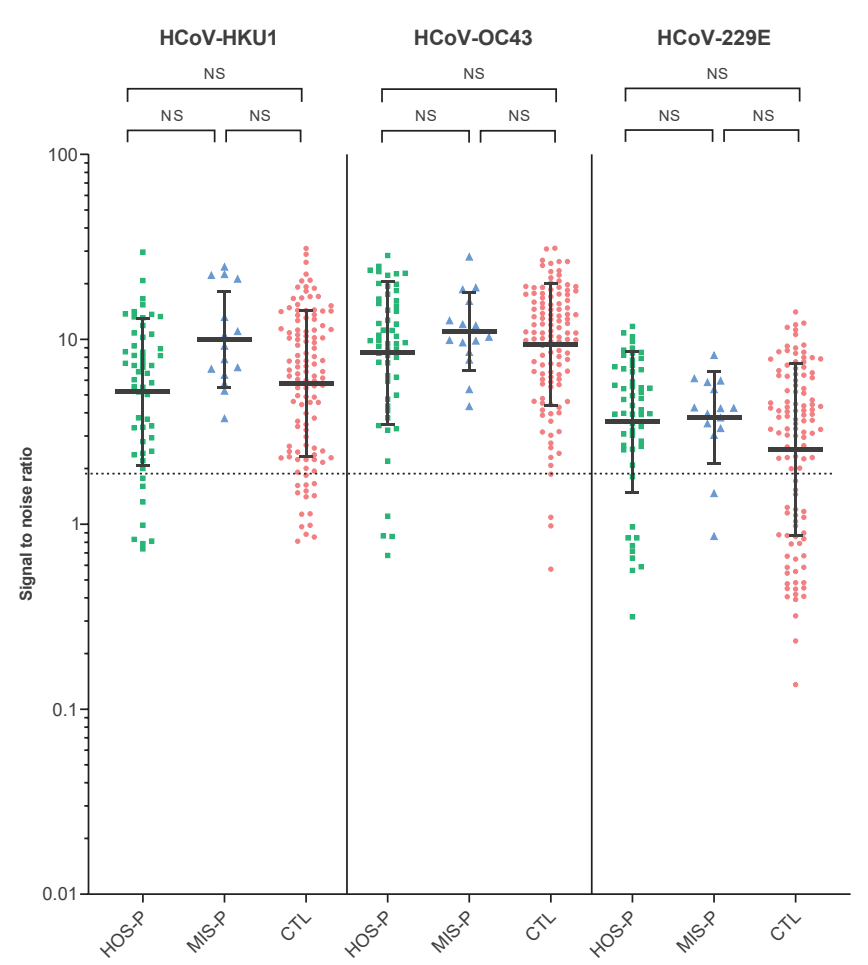

B. C-terminal domain of $\mathrm{N}$

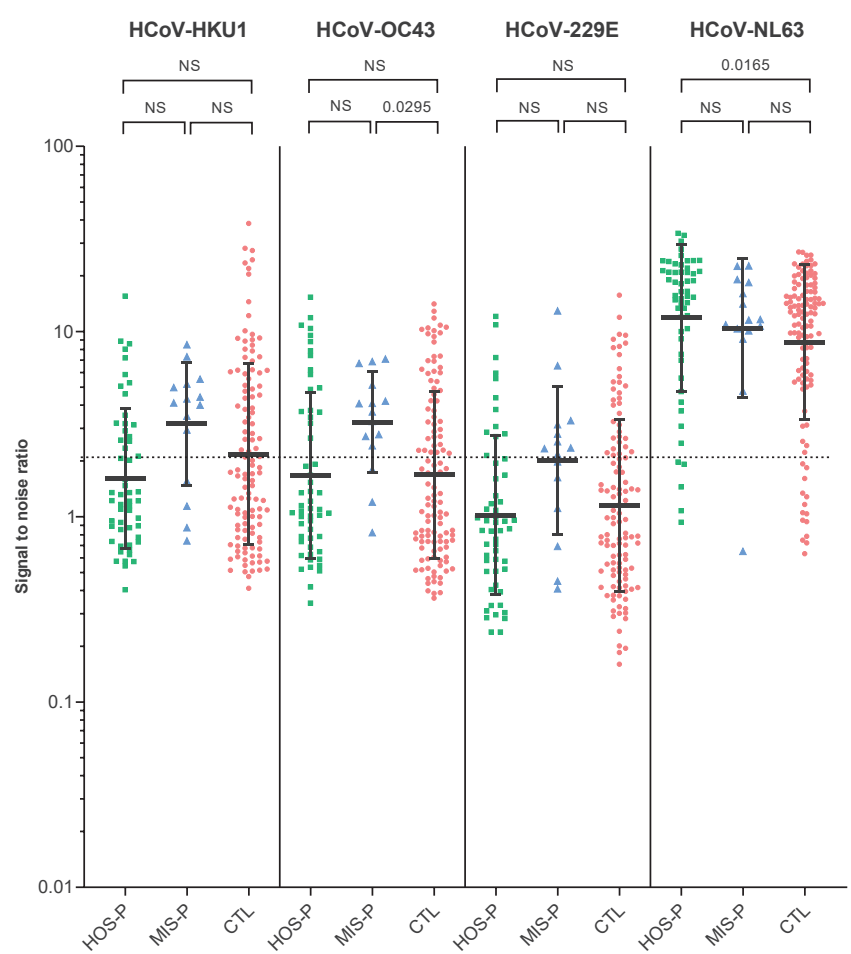

CTL: SARS-CoV-2-seronegative control group; HCoV: human coronavirus; HOS-P: SARS-CoV-2-seropositive hospitalised patients who did not develop an MIS; MIS-P: SARS-CoV-2-seropositive patients with multisystemic inflammatory syndrome; N: nucleoprotein; NS: non-significant; S: spike.

Green: HOS-P; blue: MIS-P; pink: CTL. Antibodies directed against full S ectodomain and N domain are described for each group of patients. The Kruskal-Wallis ANOVA and Dunn's multiple comparisons tests were performed for each antigen considered to compare the level of antibody response between the three groups.

Indeed, a recent study showed that protective immunity against the four coronaviruses was short-lasting [32]. Our results therefore cast doubt on whether the systemic humoral response against SARS-CoV-2 can be a good indicator of herd immunity, even if the prevalence of antibodies becomes high in the population.

Multisystem inflammatory syndrome is exceptionally rare, around 25 per 100,000 childrenyounger than 5 years in North America [25]. Viral respiratory agents, including seasonal coronaviruses, have been reported as triggers for MIS [37]. In the Paris area, a 13 -fold increased incidence in MIS was reported during the first COVID-19 pandemic wave compared with the 2 previous years [23], evidenced a temporal association and strongly suggested a causal link between MIS and SARS-CoV-2 infection. We therefore analysed the SARS-CoV-2 antibody profile in MIS cases. We found higher antibody concentrations against $S_{1}$ and $\mathrm{N}$ than in HOS-P patients who experienced an asymptomatic or pauci-symptomatic infection. This was not the case for serum antibody concentrations against beta- (OC43) or alpha- (229E and NL63) coronaviruses, suggesting that this increased response is specific to SARS-CoV-2 infection. Furthermore, it has been suggested that the lack of cross-reactivity between anti-S1 antibodies of the different seasonal and SARS-CoV-2 viruses does not favour the hypothesis of SARS-CoV-2 infection boosting pre-existing $\mathrm{HCOV}$ immunity in MIS patients [35]. As a whole, our data do not support that previous $\mathrm{HCOV}$ infection facilitates SARS-CoV-2 infection and MIS-related disease. The anti-N (but not anti-S) prevalence in $\mathrm{HKU}_{1}, \mathrm{OC}_{43}$ and $229 \mathrm{E}$ infections were higher in MIS-P patients than in CTL and HOS-P patients. This was not associated with differences in quantitative anti-N or anti-S antibody responses. Higher $\mathrm{N}$ antibody frequency in MIS-P may have originated from back-boosting cross-reactivity for $\mathrm{HCoV}$ $\mathrm{N}$-specific responses as epitopes are shared between $\mathrm{HCOV}$ and SARS-CoV2 [38], and anamnestic responses to $\mathrm{HCoV}$ may influence the antibody response to SARSCoV-2 [39]. Isotype or avidity of these responses was not tested here but could help to assess functional maturation of $\mathrm{N}$-specific antibodies in future studies. 
A. SARS-CoV-2 vs HKU1 anti-S and -N antibodies

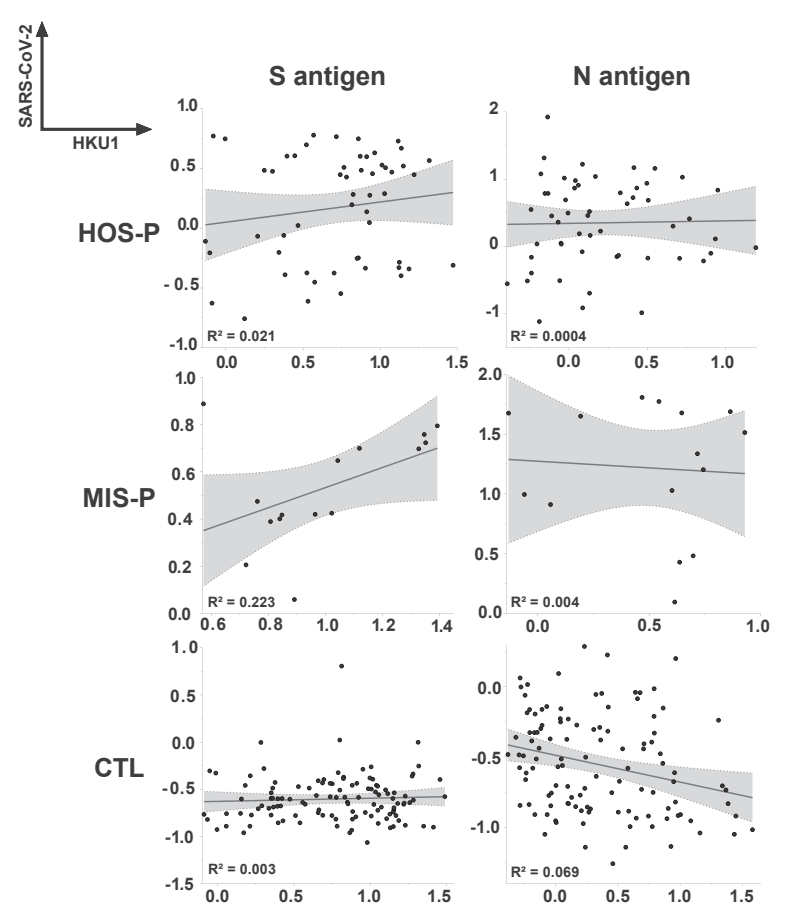

B. Principal component analysis: SARS-CoV-2 anti-S, -S1, -S2, -N vs HCoV anti-S and $-\mathrm{N}$

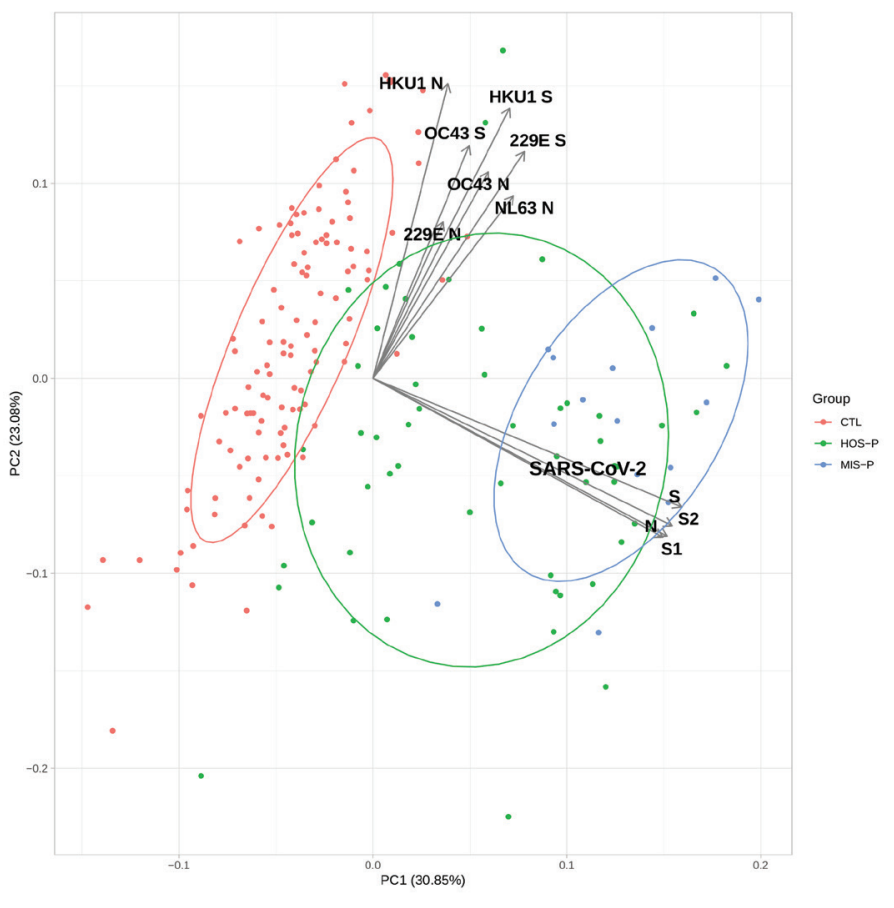

CTL: SARS-CoV-2-seronegative control group; HCoV: human coronavirus; HOS-P: SARS-CoV-2-seropositive hospitalised patients who did not develop an MIS; MIS-P: SARS-CoV-2-seropositive patients with multisystemic inflammatory syndrome; N: nucleoprotein; S: spike; SARSCoV-2: severe acute respiratory syndrome coronavirus 2.

The principal component analysis shows that (i) the distribution of all antibodies against SARS-CoV-is 2 mainly correlated with the $\mathrm{x}$-axis and those corresponding to seasonal HCoV with the y-axis and (ii) antibodies against seasonal HCoV do not separate HOS-P and MIS-P from CTL children. This demonstrates the independence of antibody responses between SARS-CoV-2 and HCoV.

In addition, we acknowledge that we could have failed to identify a succession of events, for example the time period between a first infection with an $\mathrm{HCoV}$ and the SARS-CoV-2 infection, which may have led to a specific pattern of antibodies and contributed to MIS physiopathology.

Most of the patients reported no symptoms suggestive of acute COVID-19 disease and most had positive serum IgG responses. This suggests that the development of MIS in these patients probably was the result of a post-viral immunological reaction. It should also be stressed that other causes than COVID-19 can be responsible for MIS. During the first wave of the outbreak (26 April to 26 May), 30 children with MIS were admitted in our hospital, among whom 23 had a positive SARS-CoV-2 serology and seven were negative for both SARS-CoV-2 PCR and serology [40].

Our results also show that children present with a very high antibody prevalence to seasonal $\mathrm{HCoV}$, which does not impair the efficient circulation of these viruses every year, pointing to the limits of herd immunity applied to seasonal coronaviruses, and possibly SARS-CoV-2.

\section{Acknowledgements.}

We thank Thierry Rose and Yves Janin for providing us the luciferase reagents, Evelyne Dufour and Stephane Petres for their help in the production of recombinant proteins, Pierre Charneau and François Anna for testing the sera with the pseudoneutralisation test and the ICAReB platform for giving us access to a collection of sera collected before the epidemic. We thank Olivier Schwartz for providing us with the raw data of the S-Flow technique for the sera analysed in Grzelak et al., 2020. We thank Quentin Leclech for help with data analysis, and Zakary M'Sakny, Mathis Crespin, Felix Wolfram, Victor Zetlaoui (enthusiastic MD Students), Deborah Rechard, Dr Michaela Semeraro and Dr Emeline Roy (Centre d'Investigation Clinique, Hôpital Necker Enfants Malades) who helped for data collection. We thank Simon Cauchemez for critical reading of the manuscript.

Funding: ME lab is funded by Institut Pasteur, Labex IBEID (ANR-10-LABX-62-IBEID), Reacting (Research and Action Emerging Infectious Diseases), EU grant 101003589 "ReCoVer", ANR OH-ticks. SVDW lab is funded by Institut Pasteur, CNRS, Université de Paris, Santé publique France, Labex IBEID (ANR-10-LABX-62-IBEID), REACTing (Research and Action Emerging Infectious Diseases), EU Grant 101003589 RECoVER. This work was supported by the " URGENCE COVID-19 " fundraising campaign of Institut Pasteur. 
Conflict of interest

None declared.

\section{Authors' contributions}

Conceptualisation and Methodology: Isabelle SermetGaudelus, Sarah Temmam, Thomas Bigot, Thibaut Lurier, Marija Backovic, Agnès Delaunay-Moisan, Sylvie van der Werf, Marianne Leruez-Ville, Marc Eloit. Cohort management and sample collection: Vincent Gajdos, Elsa Foucaud, Bettina Mesplées, Grégoire Benoist, Albert Faye, Marc DuvalArnould, Célia Cretolle, Marina Charbit, Mélodie Aubart, Johanne Auriau, Mathie Lorrot, Dulanjalee Kariyawasam, Laura Fertitta, Gilles Orliaguet, Bénédicte Pigneur, Tiffany Guilleminot, Brigitte Bader-Meunier, Coralie Briand, Julie Toubiana. Serological and seroneutralisation assays: Sarah Temmam, Christèle Huon, Sylvie Behillil, Delphine Chrétien, Flora Donati, Mélanie Albert, Vincent Enouf. Data assembly and manuscript writing: Isabelle Sermet-Gaudelus, Sarah Temmam, Sylvie van der Werf, Marc Eloit. Funding acquisition: Isabelle Sermet-Gaudelus, Sylvie van der Werf, Marc Eloit. Supervision: Isabelle Sermet-Gaudelus, Sylvie van der Werf, Marc Eloit. All authors reviewed and approved the final version of the manuscript.

\section{References}

1. Coronaviridae Study Group of the International Committee on Taxonomy of Viruses. The species Severe acute respiratory syndrome-related coronavirus: classifying $2019-\mathrm{nCoV}$ and naming it SARS-CoV-2. Nat Microbiol. 2020;5(4):536-44. https://doi.org/10.1038/s41564-020-0695-z PMID: 32123347

2. Bialek S, Gierke R, Hughes M, McNamara LA, Pilishvili T, Skoff T,, et al. Coronavirus disease 2019 in children - United States, February 12-April 2, 2020. MMWR Morb Mortal Wkly Rep. 2020;69(14):422-6. https://doi.org/10.15585/mmwr. mm6914e4 PMID: 32271728

3. Lu X, Zhang L, Du H, Zhang J, Li YY, Qu J, et al. SARS-CoV-2 Infection in Children. N Engl J Med. 2020;382(17):1663-5. https://doi.org/10.1056/NEJMc2005073 PMID: 32187458

4. Dong Y, Mo X, Hu Y, Qi X, Jiang F, Jiang Z, et al. Epidemiology of COVID-19 among children in China. Pediatrics. 2020;145(6):e20200702. https://doi.org/10.1542/peds.20200702 PMID: 32179660

5. Wu Z, McGoogan JM. Characteristics of and important lessons from the coronavirus disease 2019 (COVID-19) outbreak in China: summary of a report of 72314 cases from the Chinese Center for Disease Control and Prevention. JAMA. 2020;323(13):1239-42. https://doi.org/10.1001/ jama.2020.2648 PMID: 32091533

6. Choi S-H, Kim HW, Kang J-M, Kim DH, Cho EY. Epidemiology and clinical features of coronavirus disease 2019 in children. Clin Exp Pediatr. 2020;63(4):125-32. https://doi.org/10.3345/ cep.2020.00535 PMID: 32252139

7. Jones TC, Mühlemann B, Veith T, Biele G, Zuchowski $M$, Hoffmann J, et al. An analysis of SARS-CoV-2 viral load by patient age; medRxiv. 2020. http://dx.doi. org/2020.06.08.20125484

8. Guan WJ, Ni ZY, Hu Y, Liang WH, Ou CQ, He JX, et al. Clinical characteristics of coronavirus disease 2019 in China. N Eng J Med. 2020;382(18):1708-20. https://doi.org/10.1056/ NEJMoa2002032 PMID: 32109013

9. Danis K, Epaulard O, Bénet T, Gaymard A, Campoy S, Botelho-Nevers E, et al. Cluster of coronavirus disease 2019 (COVID-19) in the French Alps, February 2020. Clin Infect Dis. 2020;71(15):825-32. https://doi.org/10.1093/cid/ciaa424 PMID: 32277759

10. Lopez AS, Hill M, Antezano J, Vilven D, Rutner T, Bogdanow L, et al. Transmission dynamics of COVID-19 outbreaks associated with child care facilities - Salt Lake City, Utah, April-July 2020. MMWR Morb Mortal Wkly Rep. 2020;69(37):1319-23. https:// doi.org/10.15585/mmwr.mm6937e3 PMID: 32941418

11. Yu C, Zhou M, Liu Y, Guo T, Ou C, Yang L, et al. Characteristics of asymptomatic COVID-19 infection and progression: A multicenter, retrospective study. Virulence. 2020;11(1):1006 14. https://doi.org/10.1080/21505594.2020.1802194 PMID: 32722990
12. Su L, Ma X, Yu H, Zhang Z, Bian P, Han Y, et al. The different clinical characteristics of corona virus disease cases between children and their families in China - the character of children with COVID-19. Emerg Microbes Infect. 2020;9(1):707-13. https://doi.org/10.1080/22221751.2020.1744483 PMID: 32208917

13. Viner RM, Mytton OT, Bonell C, Melendez-Torres GJ, Ward J, Hudson L, et al. Susceptibility to SARS-CoV-2 infection among children and adolescents compared with adults: a systematic review and meta-analysis. JAMA Pediatr. 2020. 175(2):143-56. https://doi.org/10.1001/jamapediatrics.2020.4573 PMID: 32975552

14. Sinaei R, Pezeshki S, Parvaresh S, Sinaei R. Why COVID-19 is less frequent and severe in children: a narrative review. World J Pediatr. 2021;17(1):10-20. https://doi.org/10.1007/s12519-02000392-y PMID: 32978651

15. Zhou W, Wang W, Wang H, Lu R, Tan W. First infection by all four non-severe acute respiratory syndrome human coronaviruses takes place during childhood. BMC Infect Dis. 2013;13(1):433. https://doi.org/10.1186/1471-2334-13-433 PMID: 24040960

16. K. Ng, N. Faulkner, G. Cornish, A. Rosa, C. Earl, A. Wrobel, et al. Pre-existing and de novo humoral immunity to SARS-CoV-2 in humans; bioRxiv 2020. http://dx.doi.org/2020.05.14.095414

17. Grifoni A, Weiskopf D, Ramirez SI, Mateus J, Dan JM, Moderbacher CR, et al. Targets of T cell responses to SARSCoV-2 coronavirus in humans with COVID-19 disease and unexposed individuals. Cell. 2020;181(7):1489-1501.e15. https://doi.org/10.1016/j.cell.2020.05.015 PMID: 32473127

18. J. Braun, L. Loyal, M. Frentsch, D. Wendisch, P. Georg, F. Kurth, et al. Presence of SARS-CoV-2 reactive T cells in COVID-19 patients and healthy donors; medRxiv 2020. http://dx.doi. org/2020.04.17.20061440

19. Verdoni L, Mazza A, Gervasoni A, Martelli L, Ruggeri M, Ciuffreda $M$, et al. An outbreak of severe Kawasaki-like disease at the Italian epicentre of the SARS-CoV-2 epidemic: an observational cohort study. Lancet. 2020;395(10239):17718. https://doi.org/10.1016/S0140-6736(20)31103-X PMID: 32410760

20. Belhadjer Z, Méot M, Bajolle F, Khraiche D, Legendre A, Abakka $S$, et al. Acute heart failure in multisystem inflammatory syndrome in children in the context of global SARS-CoV-2 pandemic. Circulation. 2020;142(5):429-36. https://doi. org/10.1161/CIRCULATIONAHA.120.048360 PMID: 32418446

21. Takada A, Kawaoka Y. Antibody-dependent enhancement of viral infection: molecular mechanisms and in vivo implications. Rev Med Virol. 2003;13(6):387-98. https://doi.org/10.1002/ rmv.405 PMID: 14625886

22. Riphagen S, Gomez X, Gonzalez-Martinez C, Wilkinson N, Theocharis $P$. Hyperinflammatory shock in children during COVID-19 pandemic. Lancet. 2020;395(10237):1607-8. https:// doi.org/10.1016/S0140-6736(20)31094-1 PMID: 32386565

23. Toubiana J, Poirault C, Corsia A, Bajolle F, Fourgeaud J, Angoulvant F, et al. Kawasaki-like multisystem inflammatory syndrome in children during the covid-19 pandemic in Paris, France: prospective observational study. BMJ. 2020;369:m2094. https://doi.org/10.1136/bmj.m2094 PMID: 32493739

24. M. H. Cheng, S. Zhang, R. A. Porritt, M. Arditi, I. Bahar. An insertion unique to SARS-CoV-2 exhibits superantigenic character strengthened by recent mutations; bioRxiv 2020. http://dx.doi.org/2020.05.21.109272

25. McCrindle BW, Rowley AH, Newburger JW, Burns JC, Bolger AF, Gewitz M, et al. Diagnosis, treatment, and long-term management of Kawasaki disease: a scientific statement for health professionals from the American Heart Association. Circulation. 2017;135(17):e927-99. https://doi.org/10.1161/ CIR.0000000000000484 PMID: 28356445

26. Grzelak L, Temmam S, Planchais C, Demeret C, Tondeur L, Huon $C$, et al. A comparison of four serological assays for detecting anti-SARS-CoV-2 antibodies in human serum samples from different populations. Sci Transl Med. 2020;12(559):eabc3103. https://doi.org/10.1126/scitranslmed.abc3103 PMID: 32817357

27. R Core Team. R: A Language and Environment for Statistical Computing. Vienna: R Foundation for Statistical Computing; 2020. Available from: https://www.R-project.org/

28. Dijkman R, Jebbink MF, El Idrissi NB, Pyrc K, Müller MA, Kuijpers TW, et al. Human coronavirus NL63 and 229E seroconversion in children. J Clin Microbiol. 2008;46(7):2368 73. https://doi.org/10.1128/JCM.00533-08 PMID: 18495857

29. Garbino J, Crespo S, Aubert J-D, Rochat T, Ninet B, Deffernez C, et al. A prospective hospital-based study of the clinical impact of non-severe acute respiratory syndrome (Non-SARS)-related human coronavirus infection. Clin Infect Dis. 2006;43(8):100915. https://doi.org/10.1086/507898 PMID: 16983613 
30. Greenberg SB. Update on rhinovirus and coronavirus infections. Semin Respir Crit Care Med. 2011;32(4):433-46. https://doi.org/10.1055/s-0031-1283283 PMID: 21858748

31. Su S, Wong G, Shi W, Liu J, Lai ACK, Zhou J, et al. Epidemiology, genetic recombination, and pathogenesis of coronaviruses. Trends Microbiol. 2016;24(6):490-502. https://doi org/10.1016/j.tim.2016.03.003 PMID: 27012512

32. Huang AT, Garcia-Carreras B, Hitchings MDT, Yang B, Katzelnick LC, Rattigan SM, et al. A systematic review of antibody mediated immunity to coronaviruses: kinetics, correlates of protection, and association with severity. Nat Commun. 2020;11(1):4704. https://doi.org/10.1038/s41467-020-18450-4 PMID: 32943637

33. Severance EG, Bossis I, Dickerson FB, Stallings CR, Origoni $A E$, Sullens A, et al. Development of a nucleocapsid-based human coronavirus immunoassay and estimates of individuals exposed to coronavirus in a U.S. metropolitan population. Clin Vaccine Immunol. 2008;15(12):1805-10. https://doi. org/10.1128/CVI.00124-08 PMID: 18945884

34. van der Hoek L, Pyrc K, Berkhout B. Human coronavirus NL63, a new respiratory virus. FEMS Microbiol Rev. 2006;30(5):76073. https://doi.org/10.1111/j.1574-6976.2006.00032.x PMID: 16911043

35. S. Khan, R. Nakajima, A. Jain, R. R. de Assis, A. Jasinskas, J. M. Obiero, et al. Analysis of serologic cross-reactivity between common human coronaviruses and SARS-CoV-2 using coronavirus antigen microarray; bioRxiv 2020. http://dx.doi. org/2020.03.24.006544

36. Y. Peng, A. J. Mentzer, G. Liu, X. Yao, Z. Yin, D. Dong, W., et al. Broad and strong memory CD4+ and CD $8+T$ cells induced by SARS-CoV-2 in UK convalescent COVID-19 patients; bioRxiv 2020. http://dx.doi.org/2020.06.05.134551

37. Esper F, Shapiro ED, Weibel C, Ferguson D, Landry ML, Kahn JS Association between a novel human coronavirus and Kawasaki disease. J Infect Dis. 2005;191(4):499-502. https://doi. org/10.1086/428291 PMID: 15655771

38. Galipeau Y, Greig M, Liu G, Driedger M, Langlois M-A. Humoral responses and serological assays in SARS-CoV-2 infections. Front Immunol. 2020;11:610688. https://doi.org/10.3389/ fimmu.2020.610688 PMID: 33391281

39. Shrock E, Fujimura E, Kula T, Timms RT, Lee I-H, Leng Y, et al. Viral epitope profiling of COVID-19 patients reveals cross-reactivity and correlates of severity. Science.

2020;370(6520):eabd4250. https://doi.org/10.1126/science. abd4250 PMID: 32994364

40. Toubiana J, Cohen JF, Brice J, Poirault C, Bajolle F, Curtis W, et al. Distinctive features of Kawasaki disease following SARS CoV-2 infection: a controlled study in Paris, France. J Clin Immunol. 2021;41(3):526-35. https://doi.org/10.1007/s10875020-00941-0 PMID: 33394320

\section{License, supplementary material and copyright}

This is an open-access article distributed under the terms of the Creative Commons Attribution (CC BY 4.0) Licence. You may share and adapt the material, but must give appropriate credit to the source, provide a link to the licence and indicate if changes were made.

Any supplementary material referenced in the article can be found in the online version.

This article is copyright of the authors or their affiliated institutions, 2021. 